\title{
Tumor Antigen-Specific FOXP3+ CD4 T Cells Identified in Human Metastatic Melanoma: Peptide Vaccination Results in Selective Expansion of Th1-like Counterparts
}

\author{
Camilla Jandus,' Gilles Bioley, Danijel Dojcinovic, Laurent Derré, Lukas Baitsch,' \\ Sébastien Wieckowski, ${ }^{2}$ Nathalie Rufer, ${ }^{2}$ William W. Kwok, ${ }^{5}$ Jean-Marie Tiercy, ${ }^{6}$ \\ Immanuel F. Luescher, ${ }^{4}$ Daniel E. Speiser, ${ }^{1,3}$ and Pedro Romero ${ }^{1,3}$ \\ ${ }^{1}$ Division of Clinical Onco-Immunology, Ludwig Institute for Cancer Research Ltd., Lausanne Branch, Hôpital Orthopédique \\ and ${ }^{2}$ Department of Research CHUV, Faculty of Biology and Medicine, University of Lausanne, Lausanne, Switzerland; ${ }^{3}$ National Center \\ for Competence in Research, Molecular Oncology and ${ }^{4}$ Molecular Immunology Group, Ludwig Institute for Cancer Research Ltd., \\ Lausanne Branch, Epalinges, Switzerland; ${ }^{5}$ Benaroya Research Institute at Virginia Mason, Seattle, Washington; and ${ }^{\circ}$ National Reference \\ Laboratory for Histocompatibility, Transplantation Immunology Unit, Division of Immunology and Allergology, University Hospital, \\ Geneva, Switzerland
}

\begin{abstract}
We have previously shown that vaccination of HLA-A2 metastatic melanoma patients with the analogue Melan-

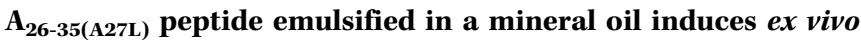
detectable specific CD8 $T$ cells. These are further enhanced when a TLR9 agonist is codelivered in the same vaccine formulation. Interestingly, the same peptide can be efficiently recognized by HLA-DQ6-restricted CD4 T cells. We used HLADQ6 multimers to assess the specific CD4 T-cell response in both healthy individuals and melanoma patients. We report that the majority of melanoma patients carry high frequencies of naturally circulating HLA-DQ6-restricted Melan-A-specific CD4 T cells, a high proportion of which express FOXP3 and proliferate poorly in response to the cognate peptide. Upon vaccination, the relative frequency of multimer+ $\mathrm{CD} 4 \mathrm{~T}$ cells did not change significantly. In contrast, we found a marked shift to FOXP3-negative CD4 $T$ cells, accompanied by robust CD4 T-cell proliferation upon in vitro stimulation with cognate peptide. A concomitant reduction in TCR diversity was also observed. This is the first report on direct ex vivo identification of antigen-specific FOXP3 + T cells by multimer labeling in cancer patients and on the direct assessment of the impact of peptide vaccination on immunoregulatory $T$ cells. [Cancer Res 2009;69(20):8085-93]
\end{abstract}

\section{Introduction}

Specific immunotherapy is a promising approach (1-3) to the treatment of a wide range of medical conditions including chronic viral diseases, autoimmune inflammatory disorders, and various types of cancer. The discovery of tumor-associated antigens recognized by conventional $\alpha \beta \mathrm{T}$ cells provided the foundation for the design of defined antigen-based cancer vaccines (4). Important to the process of rational vaccine development,

Note: Supplementary data for this article are available at Cancer Research Online (http://cancerres.aacrjournals.org/).

Current address for G. Bioley: R \& D Laboratory of the Division of Immunology and Allergy, Centre Hospitalier Universitaire Vaudois (CHUV), 1011 Lausanne, Switzerland.

Requests for reprints: Pedro Romero, Division of Clinical Onco-Immunology, Ludwig Institute for Cancer Research Ltd., Hôpital Orthopédique Niv. 5-aile est, Av. Pierre Decker 4, 1011 Lausanne, Switzerland. Phone: 41-21-314-01-98; Fax: 41-21314-74-77; E-mail: pedro.romero@licr.unil.ch.

(C)2009 American Association for Cancer Research.

doi:10.1158/0008-5472.CAN-09-2226 monitoring of antigen-specific T-cell responses helps guiding vaccine optimization.

A large number of clinical trials using T-cell-defined antigens have been reported in practically all types of cancer (5). Metastatic melanoma is however the best studied tumor type in terms of immune reactivity and experimental vaccine testing (6). Among the numerous antigens expressed by cutaneous melanoma, Melan-A/ Mart-1 (hereafter Melan-A) is one of the best characterized thus far. The Melan- $A$ gene encodes a 118 amino acid long polypeptide expressed by normal melanocytes and the majority of primary and metastatic tumors (7). Interestingly, most of the Melan-A-specific T-cell responses identified in advanced tumor-bearing patients focus on the region spanning residues 20 to 40 . In particular, the peptide 26 to 35 defines epitopes recognized by HLA-A2- and HLAB35-restricted CD8 T cells (8-10). Slightly longer peptides containing the same core sequence are recognized by HLA-B45 (11) and $-\mathrm{B} 44^{7}$ restricted CD8 T cells. Moreover, the 25 to 36 dodecapeptide is recognized by HLA-DQ6-, HLA-DQ3-, and HLA-DR3-restricted CD4 T cells (12). This pronounced bias in processing and presentation of the Melan-A antigens is reminiscent of immunodominant protein regions and lends itself to detailed analysis of melanoma-specific CD8 and CD4 T-cell responses in defined clinical situations such as tumor progression, tumor cell death provoked by chemotherapy or radiotherapy, and in the course of immunotherapy. More importantly, such immunodominant region(s) are excellent candidates for peptide-based vaccines because of the promise to efficiently promote integrated protective T-cell responses (13-16).

We have shown that the natural Melan- $\mathrm{A}_{26-35}$ decapeptide binds weakly to the HLA-A2 molecule because of the lack of a strong anchor residue at position P2. The replacement of Ala at position 27 for Leu results in enhanced binding to HLA-A2, in 2- to 3-log increase of its relative antigenicity and, more importantly, to an increased immunogenicity (17). Vaccination of metastatic melanoma patients with the peptide analogue Melan- $\mathrm{A}_{26-35(\mathrm{~A} 27 \mathrm{~L})}$ emulsified in mineral oil resulted in high frequencies of Melan-A-specific CD8 $\mathrm{T}$ cells that can be detected by direct ex vivo flow cytometry analysis using HLA-A2/Melan-A peptide multimers in $\sim 60 \%$ of vaccinated patients $(18,19)$. Moreover, vaccination efficiency can be dramatically enhanced by inclusion of the TLR9 agonist ODNCpG type B 7909/PF-3512676 in the immunizing emulsion. In this 
case, strong specific CD8 T-cell responses as measured by multimer labeling developed rapidly in all vaccinated patients (20).

A search for CD4 T-cell epitopes in the Melan-A polypeptide revealed that a dodecapeptide spanning the region 25 to 36 was optimally recognized by Melan-A-specific and tumor-reactive CD4 T cells isolated from melanoma patients (12). Moreover, HLA-DQ6/ Melan- $\mathrm{A}_{25-36}$ multimers directly identified specific CD4 $\mathrm{T}$ cells by flow cytometry. Interestingly, this optimal CD4 T-cell epitope fully encompasses the HLA-A2-restricted decapeptide Melan- $\mathrm{A}_{26-35}$. In this report, we used HLA-DQ6/Melan-A peptide multimers to analyze in detail Melan-A-specific CD4 T-cell responses in healthy individuals (HD) and a cohort of HLA-A*0201 metastatic melanoma patients who shared expression of the HLA-DQB1*0602 allele. We found relatively high frequencies of circulating HLA-DQ6/Melan-A multimer+ CD4 T cells in most melanoma patients studied. Fine specificity studies of a series of clones isolated from some of these patients showed efficient cross-recognition of the enhanced Melan-

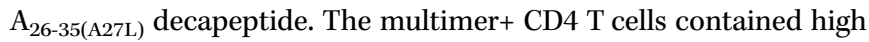
proportions of FOXP3+ cells in the blood samples before peptide vaccination. In contrast, the proportions of FOXP3+ cells were markedly reduced among the multimer+ $\mathrm{CD} 4 \mathrm{~T}$ cells, but not in the multimer- fractions, in blood samples obtained during the course of Melan-A peptide vaccination. Thus, although vaccination elicited the intended HLA-A2-restricted CD8 T-cell response, it also triggered an unexpected effect on specific CD4 T cells in the subset of HLA-DQ6-vaccinated patients.

\section{Materials and Methods}

Cells and tissues. Peripheral blood and metastatic lymph nodes were obtained from melanoma patients upon informed consent. Clinical characteristics and treatments of the patients included in the study are described in Table 1. Treatments of the patients were approved by the institutional review board of the University Hospital of Lausanne, Swiss
Medic and the Ludwig Institute for Cancer Research Ltd. The healthy subjects were blood donors at the Blood transfusion Center in Bern, Switzerland. Mononuclear cells were purified by density gradient and immediately frozen, as previously described (21). Genomic DNA was extracted from frozen peripheral blood mononuclear cells (PBMC) and all individuals were molecularly typed for HLA-DQB1*0602 by reverse PCR-sequencespecific oligonucleotides hybridization on microbeads arrays (LabType, OneLambda), using the luminex technology. Lymphocytes were maintained in culture as already described (12).

Generation of pMHC I and II multimers; monoclonal antibodies and labeling. The generation of HLA-DQB1*0602 multimers was performed as already described using the Melan- $\mathrm{A}_{25-36}$, Melan- $\mathrm{A}_{26-35(\mathrm{~A} 27 \mathrm{~L})}$, or the $\mathrm{HA}_{57-75}$ peptides (12). Multimer labeling was performed for $1 \mathrm{~h}$ at $37^{\circ} \mathrm{C}$ before staining with fluorescent monoclonal antibodies $(\mathrm{mAb})$ directed against surface molecules $\left(20 \mathrm{~min}\right.$ at $\left.4^{\circ} \mathrm{C}\right)$. FOXP3 labeling was performed according to manufacturer's recommendations. Cells were analyzed by flow cytometry on a LSR II. For analysis, dead cells were excluded using either propidium iodide (Sigma-Aldrich) or ethidium monoazide (Molecular Probes), and all dot plots shown were gated on live CD3+ cells. All mAbs were purchased from BD Bioscience, with exception for anti-human FOXP3 and anti-human IL-17 mAbs (eBioscience). HLA-A*0201/Melan- $\mathrm{A}_{26-35(\mathrm{~A} 27 \mathrm{~L})}$ multimers were produced as described (22). Multimer labeling was performed for $45 \mathrm{~min}$ at $4^{\circ} \mathrm{C}$.

Intracellular cytokine staining of Melan- $\mathrm{A}_{25-36} \mathrm{CD4} \mathrm{T}$ cells. In vitro peptide stimulations were tested for the presence of cytokine-secreting CD4 T cells. Cells were stimulated for $6 \mathrm{~h}$ in the presence or absence of $2 \mu \mathrm{mol} / \mathrm{L}$ Melan- $A_{25-36}$, Melan- $A_{26-35(A 27 L)}$, or irrelevant peptide. Where indicated, purified anti-DR (L243), anti-DP (B7.21.7), or anti-DQ (SPVL3) were used to specifically block MHCII recognition $(10 \mu \mathrm{g} / \mathrm{mL})$. BrefeldinA was added after the first hour of incubation $(10 \mu \mathrm{g} / \mathrm{mL})$. After incubation and washing, cells were stained with anti-CD4 antibody, then fixed and stained intracellularly with anti-IFN $\gamma$, anti-IL-17 and anti-tumor necrosis factor (TNF) $\alpha$ or anti-interleukin (IL)-2 antibodies in the presence of Saponin $0.1 \%$. Samples were analyzed by flow cytometry using an LSRII.

In vitro peptide stimulations with Melan- $\mathrm{A}_{25-36}$ peptide. Total PBMCs or enriched CD4 $\mathrm{T}$ cells in the presence of irradiated CD4 T cells were stimulated with $2 \mu \mathrm{mol} / \mathrm{L}$ Melan- $\mathrm{A}_{25-36}$ peptide. Two days after addition of

Table 1. Clinical characteristics of melanoma patients

\begin{tabular}{|c|c|c|c|c|c|c|}
\hline Patient & Sex & Age $^{*}$ & Stage $^{\dagger}$ & Site of metastasis & Treatments & Clinical status $^{\ddagger}$ \\
\hline LAU 50 & M & 74 & IV & $\mathrm{LN}^{\S}$ & Surgery, ILP, LUD 01-003" & PD \\
\hline LAU 203 & $\mathrm{~F}$ & 62 & III & $\mathrm{LN}$ & Surgery, ILP & CR \\
\hline LAU 212 & $\mathrm{~F}$ & 71 & III & $\mathrm{LN}$ & Surgery, ILP, LUD 96-010 & SD \\
\hline LAU 270 & $\mathrm{~F}$ & 44 & IV & LN, skin & Surgery, ILP, IFN $\alpha$, LUD 96-010 & + \\
\hline LAU 353 & $\mathrm{~F}$ & 49 & III & $\mathrm{LN}$ & Surgery, LUD LAU 353 & $\dagger$ \\
\hline LAU 390 & $\mathrm{~F}$ & 38 & IV & $\mathrm{LN}$ & Surgery, IFN $\alpha$, chemotherapy, IL-2, LUD 96-010 & $\mathrm{PD}$ \\
\hline LAU 470 & $\mathrm{~F}$ & 35 & III & LN, skin & Surgery, LUD 96-010 & $\dagger$ \\
\hline LAU 567 & $\mathrm{~F}$ & 54 & III & LN, skin & Surgery, LUD 96-010 & $\dagger$ \\
\hline LAU 618 & $\mathrm{~F}$ & 73 & III & LN, skin & Surgery, IFN $\alpha$, ILP, LUD 96-010, LUD 00-018 & $\mathrm{PD}$ \\
\hline LAU 706 & $\mathrm{~F}$ & 67 & III & LN, skin & Surgery, ILP, p40, LUD 00-018 & PD \\
\hline LAU 814 & M & 28 & III/IV & $\mathrm{LN}$ & Surgery, LUD 98-009 & SD \\
\hline
\end{tabular}

*Age at diagnosis.

† Stage according to the American Joint Committee on Cancer staging system.

$\ddagger \mathrm{PD}$, progressive disease; $\mathrm{CR}$, chronic response; SD, stable disease; $\dagger$, death.

$\S$ LN, lymph node; ILP, isolated lymph perfusion.

||Immunotherapy protocols (vaccination with): LUD 01-003 (Melan-A 26-35(A27L), NY-ESO-1 $157-165$, Mage-A10 $254-262$, Montanide, s.c.); LUD 96-010

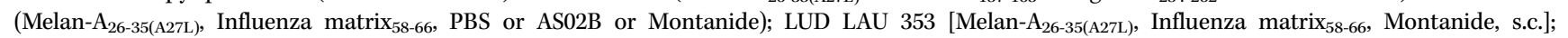

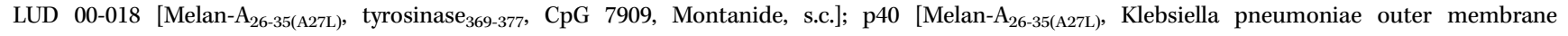
protein p40, s.c.]; LUD 98-009 [Melan-A [6-35(A27L), Mage-A10 $_{254-262}$, Montanide, s.c.].

ๆMelan- $\mathrm{A}_{26-35}$ instead of Melan- $\mathrm{A}_{26-35(\mathrm{~A} 27 \mathrm{~L})}$. 
A

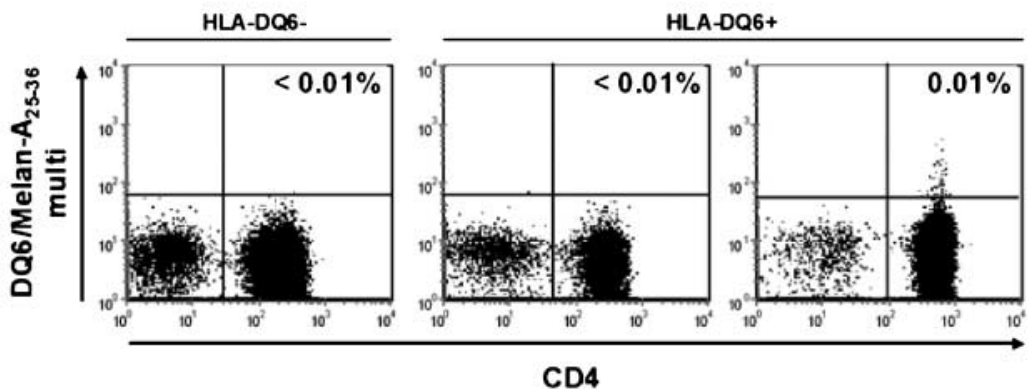

B
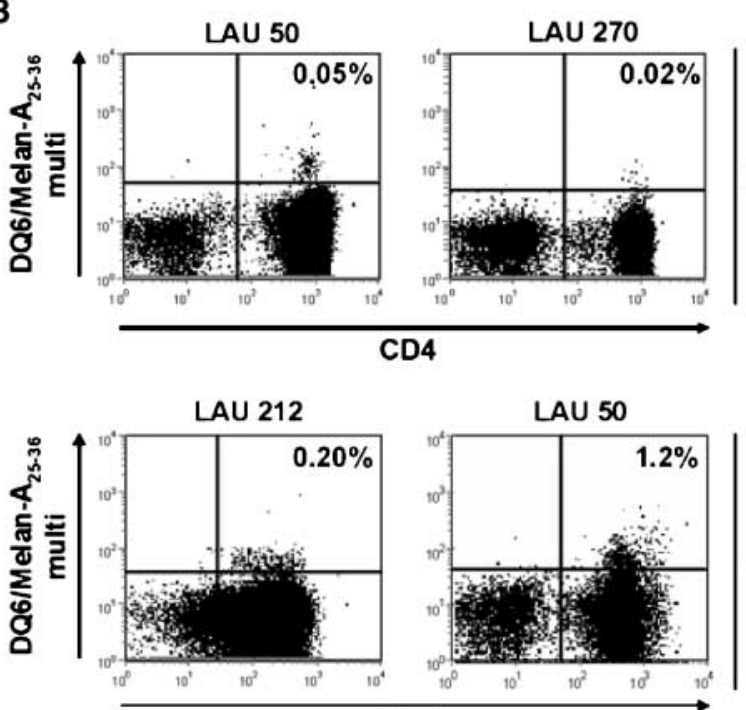

\section{LAU 50}

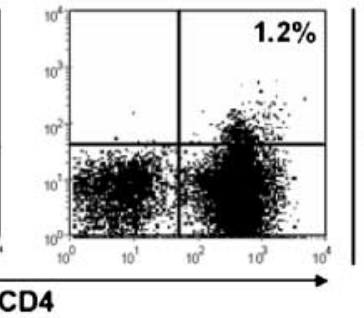

PBLs

C

TILN

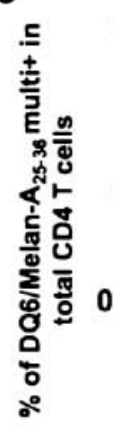

0.3

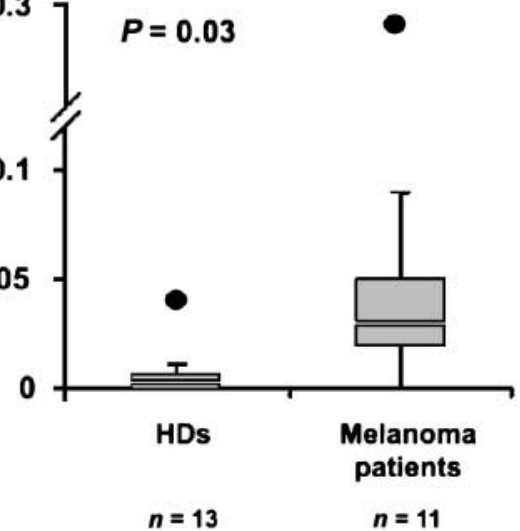

Figure 1. Ex vivo detection of Melan- $\mathrm{A}_{25-36} \mathrm{CD} 4 \mathrm{~T}$ cells in PBLs and TILNs from healthy donors and melanoma patients, before immunotherapy. A, representative examples of direct ex vivo labeling of PBLs from HLA-DQ6- (left dot plot) and HLA-DQ6+ HDs (middle and right dot plots). B, representative examples of direct

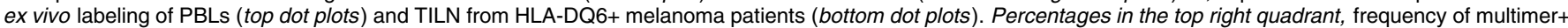
within total CD4 T cells. $C$, graph summarizing ex vivo frequencies of DQ6/Melan- $\mathrm{A}_{25-36}$ multimer+ CD4 T cells in PBLs from HLA-DQ6+ HDs and melanoma patients, before immunotherapy.

peptide, $100 \mathrm{U} / \mathrm{mL} \mathrm{IL-2} \mathrm{was} \mathrm{added} \mathrm{to} \mathrm{the} \mathrm{cultures.} \mathrm{After} 2 \mathrm{wk}$, the presence of specific CD4 T cells was assessed by DQ6/Melan- $\mathrm{A}_{25-36}$ multimers.

cDNA preparation and TCR V $\beta$ analysis. Five-cell aliquots of multimer+ cells were sorted with a FACS Vantage SE machine directly into wells of 96-V-bottomed plates. cDNA preparation, cDNA amplification, and PCR were performed as previously described (23). The quality of each sample was assessed as described before (24). Aliquots from each sample per patient and time point were pooled and subjected to individual PCR to assess the expression of the V $\beta s$ as previously published (25). Then, each five-cell sample was subjected to an individual PCR for each TCR BV chain positive in the pool.

Statistical analysis. The significance of the results was determined using Student's $t$ test. $P$ values of $<0.05$ were considered significant.

Results are represented graphically as box and whisker diagrams. Bottom and top of the boxes represent the 25th and 75th percentile, respectively; the line dividing the boxes indicate the median value, whereas the ends of the whiskers represent the maximal and minimum values, with exceptions of outliers that are shown as filled dots.

\section{Results}

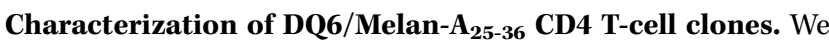
recently identified the Melan- $\mathrm{A}_{25-36}$ peptide as a naturally processed epitope presented by the human HLA-DQB ${ }^{*} 0602$ molecule
(12). We show here that CD4 T-cell clones generated from blood samples from different metastatic melanoma patients can be consistently labeled with DQ6/Melan- $\mathrm{A}_{25-36}$ multimers (Supplementary Fig. $\mathrm{S} 1 A-C$ ).

As previously reported by us using a single Melan- $\mathrm{A}_{25-36}-$ specific CD4 T-cell clone isolated from a melanoma patient, we further show here, using multiple independent DQ6/Melan- $A_{25-36}$ CD4 $\mathrm{T}$-cell clones from additional patients, that they efficiently recognize the dodecapeptide Melan- $\mathrm{A}_{25-36}$, as well as the two amino acid shorter Melan- $\mathrm{A}_{26-35(\mathrm{~A} 27 \mathrm{~L})}$ analogue decapeptide, as determined in peptide titration assays (Supplementary Fig. S2A-C).

Because the cytokine responses to DQ6/Melan- $\mathrm{A}_{25-36}$ and A2/ Melan- $\mathrm{A}_{26-35(\mathrm{~A} 27 \mathrm{~L})}$ were comparable in all experiments, we then assessed whether DQ6/Melan- $\mathrm{A}_{25-36} \mathrm{CD} 4 \mathrm{~T}$-cell clones may also be labeled using DQ6 multimers loaded with the decapeptide analogue Melan- $\mathrm{A}_{26-35(\mathrm{~A} 27 \mathrm{~L})}$. Interestingly, all the clones tested bound the DQ6/Melan- $\mathrm{A}_{26-35(\mathrm{~A} 27 \mathrm{~L})}$ multimers, whereas irrelevant clones did not (Supplementary Fig. $\mathrm{S} 2 D$ ).

Naturally acquired Melan- $A_{25-36}$ CD4 T-cell responses can be frequently detected in peripheral blood and tumor-infiltrated lymph nodes from HLA-DQ6 melanoma patients but only rarely in HDs. To directly monitor HLA-DQ6-restricted CD4 T-cell 
A

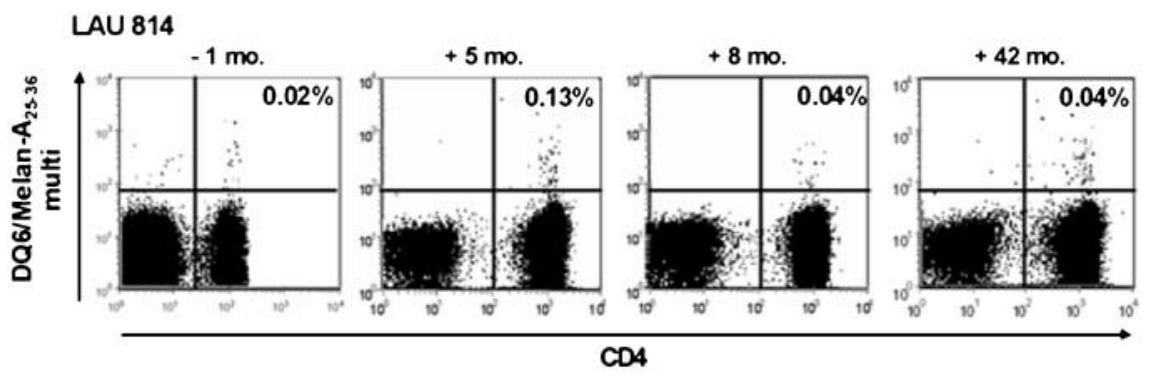

LAU 470

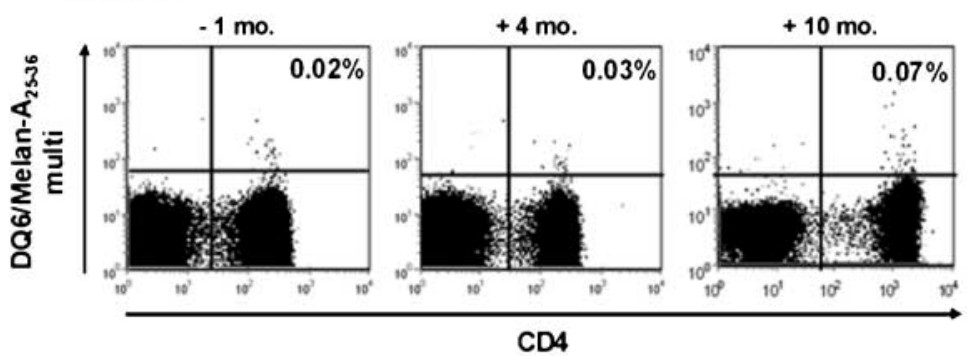

B

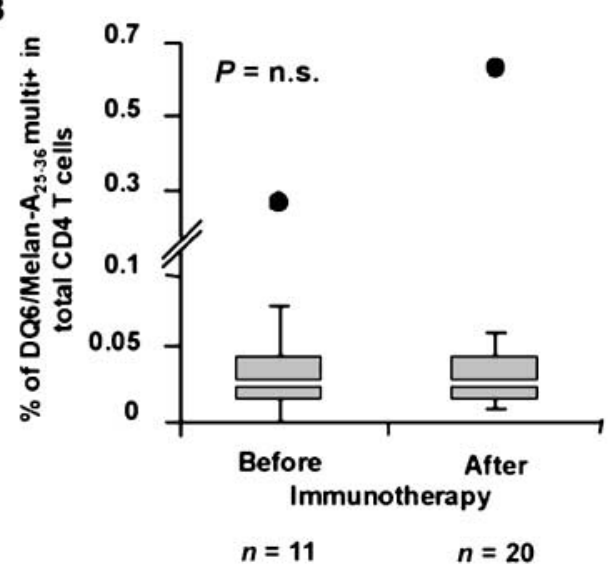

Figure 2. Ex vivo longitudinal monitoring of Melan- $\mathrm{A}_{25-36}$ multimer+ CD4 T cells in PBLs from melanoma patients during CTL-based immunotherapy. $A$, representative examples of the longitudinal evolution of ex vivo Melan- $A_{25-36}$ CD4 $T$ cells in PBLs from patients LAU 814 (top) and LAU 470 (bottom). Percentages in the top right quadrant, frequency of multimer+ within total CD4 T cells. $B$, graph summarizing ex vivo frequencies of DQ6/Melan- $\mathrm{A}_{25-36}$ multimer+ CD4 T cells in PBLs from HLA-DQ6+ melanoma patients, before and after immunotherapy. n.s., not significant. responses in humans, we first assessed the baseline frequencies of DQ6/Melan- $\mathrm{A}_{25-36}$ multimer+ CD4 T cells in lymphocytes isolated from HDs. As expected, no detectable multimer+ CD4 T cells could be observed in blood samples from 13 HLA-DQB1*0602- donors (Fig. 1A, left dot plots). In contrast, 3/13 HLA-DQB1*0602+ HDs showed low but detectable frequencies of DQ6/Melan- $\mathrm{A}_{25-36}$ CD4 $\mathrm{T}$ cells. The frequencies of positive cells were $0.01 \%, 0.01 \%$, and $0.04 \%$ for the three donors, respectively (Fig. $1 A$, middle and right dot plots). Those cells could be expanded in vitro and secreted Th1 cytokines after stimulation with cognate peptide, suggesting that they represent circulating Melan-A-specific CD4 T cells in HDs (Supplementary Fig. S3A and $B$ ). Remarkably, 10/11 HLA-DQB1*0602+ metastatic melanoma patients presented with variable, but detectable frequencies of DQ6/Melan- $\mathrm{A}_{25-36} \mathrm{CD} 4 \mathrm{~T}$ cells in peripheral blood sampled before any specific immunotherapy (Fig. $1 B$, top). Overall, the mean frequency of DQ6/Melan- $\mathrm{A}_{25-36}$ multimer+ $\mathrm{CD} 4 \mathrm{~T}$ cells was $0.005 \%$ in DQ6+ HDs and $0.06 \%(P=0.03)$ in melanoma patients (range, 0-0.29\%; Fig. $1 C$ ). In addition, we analyzed tumor-infiltrated lymph nodes (TILN) directly ex vivo from patients LAU 212 and LAU 50. This material was surgically removed in both patients before any immunotherapy. We found an enrichment of multimer+ CD4 $\mathrm{T}$ cells compared with autologous peripheral blood lymphocytes (PBL). Indeed, the frequencies of multimer+ CD4 T cells in these TILNs were $0.2 \%$ and $1.2 \%$, respectively (Fig. $1 B$, bottom).

Frequencies of DQ6/Melan- $A_{25-36}$ multimer+ CD4 $T$ cells ex vivo are not consistently modulated by $\mathrm{CD8}$ T-cell-targeted immunotherapy. As mentioned above, DQ6/Melan- $A_{25-36}$ CD4 $\mathrm{T}$ cells not only recognize the Melan- $\mathrm{A}_{25-36}$, but also the Melan$\mathrm{A}_{26-35(\mathrm{~A} 27 \mathrm{~L})}$ peptide that is recognized by HLA-A2-restricted CD8 T cells. All except one (LAU 203) of the 11 DQ6+ melanoma patients studied were included in CD8 T-cell-targeted peptide immunotherapy trials (Table 1). We therefore determined whether vac-

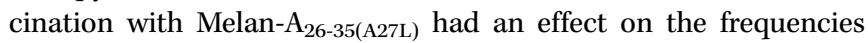
and/or function of Melan-A-specific CD4 T cells. As exemplified for two patients in Fig. $2 A$ and summarized for all the patients in Fig. $2 B$, higher levels of DQ6/Melan- $\mathrm{A}_{25-36}$ multimer+ CD4 $\mathrm{T}$ cells could be measured during vaccination (range, 0.01-0.66). Moreover, patient LAU 618 with no detectable multimer+ CD4 T cells in prevaccine PBMCs had $0.03 \%$ and $0.02 \%$ of multimer+ CD4 T cells during immunotherapy. However, no significant overall increase in 
DQ6/Melan-A ${ }_{25-36}$ multimer+ CD4 T cells could be detected $(P=0.78)$. Furthermore, the frequencies of multimer+ CD4 T cells did not correlate to the number of administered vaccines nor to the time elapsed after initiation of immunotherapy (data not shown).

To confirm that the ex vivo detected DQ6/Melan- $\mathrm{A}_{25-36}$ multimer+ CD4 $\mathrm{T}$ cells represent indeed specific cells, these cells were isolated by flow-cytometry guided sorting and cloned. Indeed, growing clones were specific for the peptide DQ6/Melan- $\mathrm{A}_{25-36}$ [in both multimer labeling as well as peptide titration assays (data not shown)].

Ex vivo FOXP3+ DQ6/Melan- $\mathrm{A}_{25-36}$ multimer+ CD4 $\mathrm{T}$ cells are consistently reduced by $\mathrm{CD8}$ T-cell-targeted immunotherapy. To assess if phenotype and function of Melan- $\mathrm{A}_{25-36}$ CD4 $\mathrm{T}$ cells might be affected by CD8 T-cell-based vaccination, we combined ex vivo multimer labeling of CD4 $\mathrm{T}$ cells with additional phenotypic and activation markers. The majority of the Melan- $\mathrm{A}_{25-36} \mathrm{CD} 4$ $\mathrm{T}$ cells displayed a memory phenotype, already before vaccination, with different degrees of activation depending on the patients. We did not observe any significant change in the expression of differentiation markers (e.g., CCR7 and CD45RA) nor in the frequency of activated cells (i.e., HLA-DR and CD38) in the postvaccination samples (data not shown).

However, remarkably, significant variations were observed in the frequency of multimer+ CD4 T cells positive for FOXP3, a marker that identifies regulatory $\mathrm{T}$ cells $(26,27)$, when comparing samples from a same patient, collected before and after vaccination. Before vaccination, large proportions (range, $19-74 \%$ ) of Melan- $\mathrm{A}_{25-36} \mathrm{CD} 4$
T cells expressed FOXP3. In contrast, only $1 \%$ to $2 \%$ of the bulk CD 4 T cells were FOXP3+ (Fig. $3 A$ and $B$ ). Strikingly, the proportion of FOXP3+ among multimer+ CD4 T cells dramatically and significantly dropped over time during vaccination in all the patients tested (range, $0-21 \% ; P<0.001$; Fig. $3 A$ and $B$ ), whereas the fraction of positive bulk CD4 T cells remained unchanged. In correlation with the significant decrease in FOXP3+ Melan- $\mathrm{A}_{25-36}$ CD4 $\mathrm{T}$ cells overtime, we observed, in these same patients, an important expansion of Melan- $\mathrm{A}_{26-35(\mathrm{~A} 27 \mathrm{~L})} \mathrm{CD} 8 \mathrm{~T}$ cells during vaccination (Fig. $3 C$ ). When assessed in HDs' samples, FOXP3 expression in ex vivo detected Melan- $\mathrm{A}_{25-36} \mathrm{CD} 4 \mathrm{~T}$ cells was low, being $7 \%, 4 \%$, and $0 \%$ in the three PBL samples analyzed (Fig. $3 A$, representative example).

The impaired in vitro proliferative CD4 T-cell response to Melan- $\mathrm{A}_{25-36}$ is restored during the course of $\mathrm{CD8} \mathrm{T}$-cell-based immunotherapy and correlates with the drop in FOXP3+ Melan- $\mathbf{A}_{25-36}$ CD4 T cells. In parallel to ex vivo detection of Melan$\mathrm{A}_{25-36} \mathrm{CD} 4 \mathrm{~T}$ cells, we assessed the functional capacities of these cells. We performed peptide in vitro stimulations (IVS) using the Melan- $\mathrm{A}_{25-36}$ peptide of enriched CD4 $\mathrm{T}$ cells from prevaccination and postvaccination PBMC samples. As shown in Fig. $4 A$, in HDs, we expanded specific cells only in those samples where ex vivo detectable Melan- $\mathrm{A}_{25-36} \mathrm{CD} 4 \mathrm{~T}$ cells were detected (HD2), whereas not in those with undetectable frequencies of Melan- $\mathrm{A}_{25-36} \mathrm{CD} 4$ $T$ cells (HD1). In melanoma patients, significant expansions were observed only in the PBMC samples collected after vaccination (Fig. $4 A$ and $B$ ), when the ex vivo frequency of FOXP3+ Melan- $\mathrm{A}_{25-36}$ CD4 T cells was below $10 \%$ of multimer+ cells (Fig. $4 A$ and $B$ ).
A
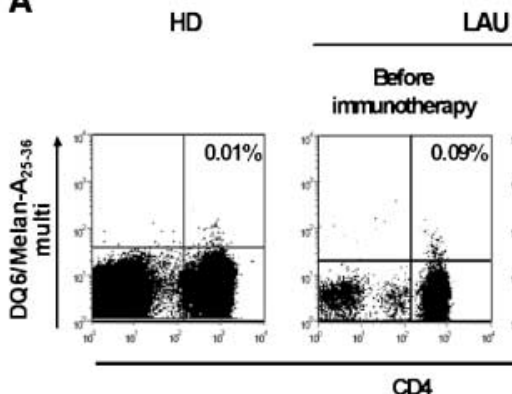

LAU 353
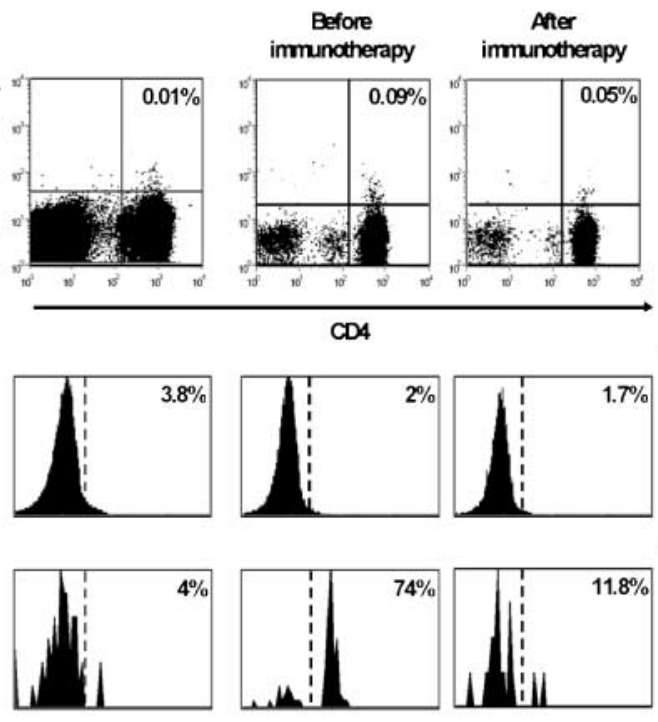

DQ69Melan $A_{253}$ specific CD4 T cells

Total CO4 T cells
B

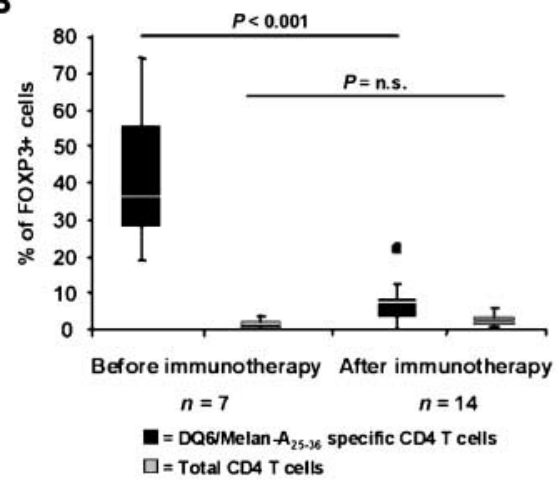

C

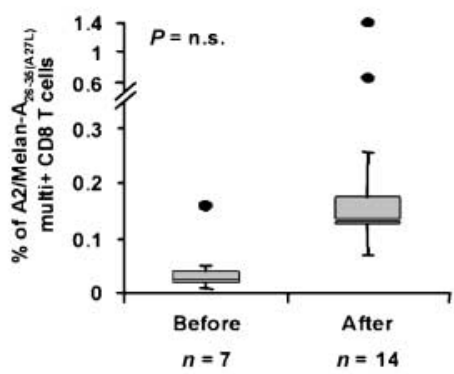

Figure 3. Significant decrease in ex vivo FOXP3+ Melan- $\mathrm{A}_{25-36}$ CD4 T cells in PBLs from melanoma patients during CTL-based immunotherapy. $A$, representative example of DQ6/Melan-A ${ }_{25-36}$ multimer labeling (top) on PBLs from a HD (left column) and patient LAU 353, before (middle column) and after immunotherapy (right column), combined with FOXP3 analysis in total (middle) or in Melan- $\mathrm{A}_{25-36} \mathrm{CD} 4 \mathrm{~T}$ cells (bottom). Percentages in the top right quadrants of the dot plots,

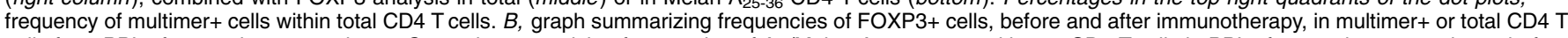

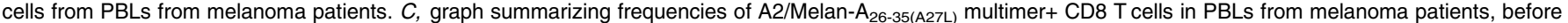
and after immunotherapy. 
Attempts to promote peptide-specific proliferation of Melan- $\mathrm{A}_{25-36}$ CD4 T cells in prevaccination PBMCs by either depleting CD4+CD25+ T cells or by adding several stimulating or inhibitory molecules in the culture wells [e.g., CpG-ODNs, CD40L, high doses IL-2, IL-6, IL-15, IL-7, anti-transforming growth factor (TGF) $\beta$, anti-IL-10 receptor] failed (data not shown).

Finally, the vigorous peptide-specific proliferative response of Melan- $\mathrm{A}_{25-36} \mathrm{CD} 4 \mathrm{~T}$ cells from samples after vaccination was matched by their ability to secrete Thl cytokines (e.g., TNF- $\alpha$ ), when incubated with the specific peptide (Fig. 4C). Cytokine secretion is abolished selectively by anti-DQ antibody but remained unaffected in the presence of anti-DP and anti-DR antibodies.

Restriction of TCR V $\beta$ usage in Melan- $A_{25-36}$ CD4 $T$ cells during CD8 T-cell-based immunotherapy. The observation that the frequencies of FOXP3+ Melan- $\mathrm{A}_{25-36} \mathrm{CD} 4 \mathrm{~T}$ cells decreases during CD8 T-cell-based immunotherapy prompted us to assess which mechanisms might underlie this phenomenon. To compare cells from the same antigen specificity at different time points, we analyzed their TCR V $\beta$ usage. We randomly selected three patients, and isolated multiple five-cell samples of ex vivo DQ6/ Melan- $\mathrm{A}_{25-36}$ multimer+ CD4 T cells by flow cytometry-guided sorting. Next, we performed PCR for the known different human TCR V $\beta$ s on these samples and compared the results for the same patient, in samples before and after immunotherapy. As shown in Fig. 5, a large panel of TCR V $\beta$ s is used by Melan- $\mathrm{A}_{25-36}$ CD4 $\mathrm{T}$ cells in all the patients, in samples before vaccination (13 by LAU 50, and 11 by both LAU 814 and LAU 470). In contrast, a smaller number of $\mathrm{V} \beta$ s could be amplified in the sorted Melan$\mathrm{A}_{25-36} \mathrm{CD} 4 \mathrm{~T}$ cells from postvaccination PBMC samples (six for LAU 814, nine for LAU 50, and two for LAU 470), suggesting a vaccination-induced restriction of the repertoire. Additional analysis of the CDR3 sequence of the amplified PCR products revealed no sequence overlap between cells sharing the same $\mathrm{V} \beta \mathrm{s}$, detected before and after vaccination, suggesting a de novo expansion of specific CD4 $\mathrm{T}$ cells with defined V $\beta$ s after immunotherapy (data not shown). Only in the case of patient LAU 814, the same clonotype (V $\beta 13$, CDR3 sequence SPHYNQPQ) was identified in two independent five-cell samples from PBMCs collected before vaccination.
A
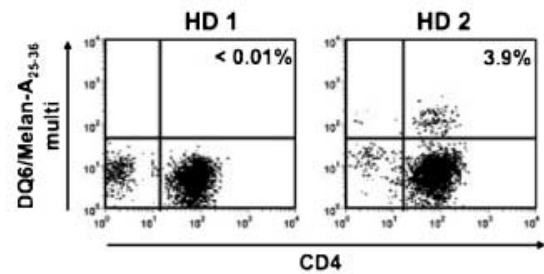

HDs
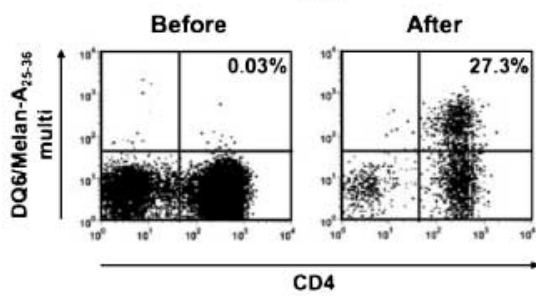

LAU 50

B

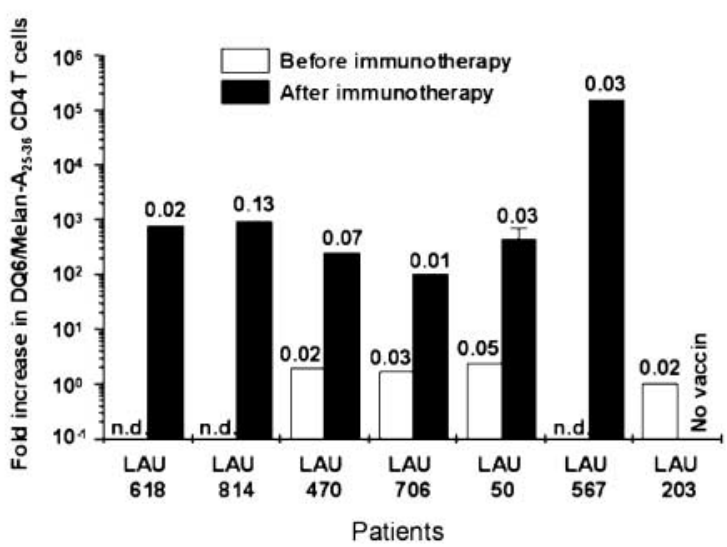

C

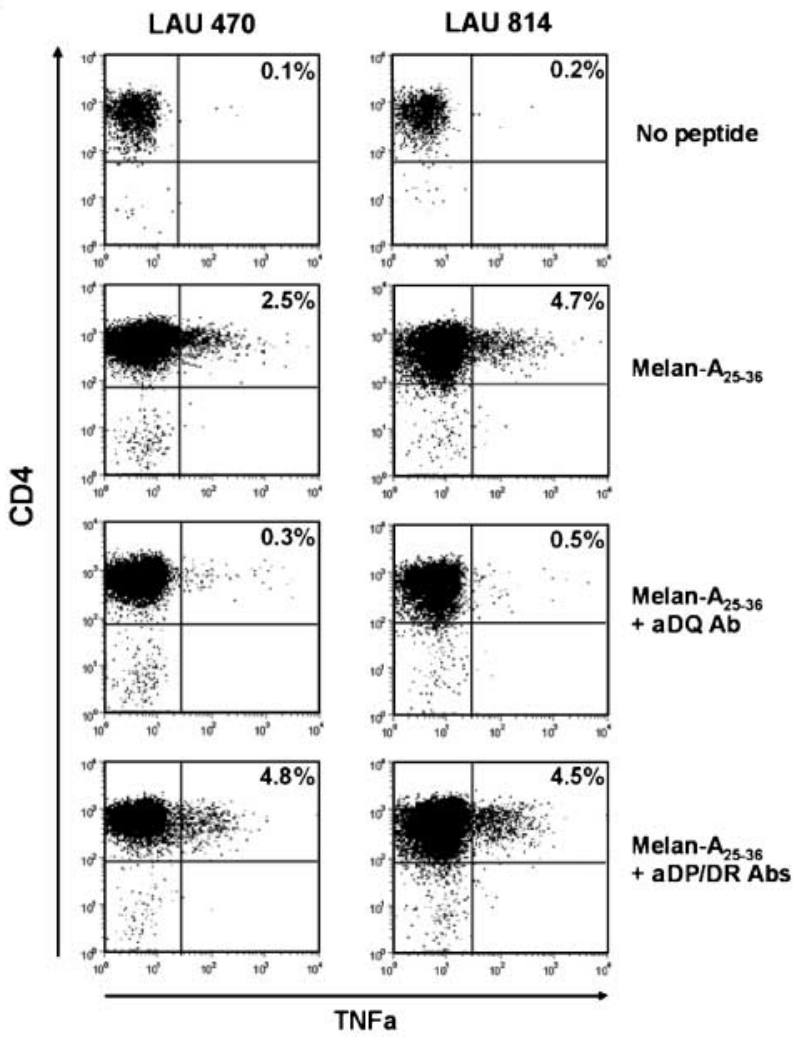

Figure 4. In vitro proliferative capacity and functional activity of Melan- $\mathrm{A}_{25-36}$ CD4 T cells from HDs and melanoma patients. $A$, CD4 T cells from HDs (top) and melanoma patients, before and after immunotherapy (bottom) were stimulated for $14 \mathrm{~d}$ in vitro with Melan- $\mathrm{A}_{25-36}$ peptide. Percentages in the top right quadrants, frequency of multimer+ cells within total CD4 T cells. $B$, summary of the expansion of Melan- $A_{25-36}$ CD4 T cells obtained by IVS of PBLs from different melanoma

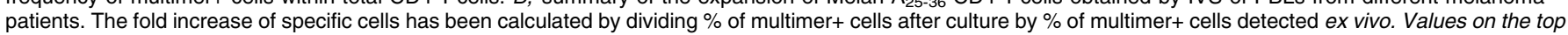

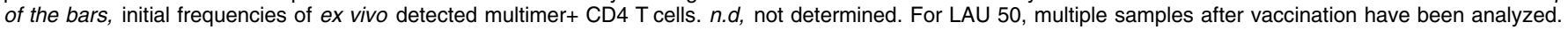
$C$, intracellular TNF $\alpha$ labeling on Melan- $\mathrm{A}_{25-36}$ in vitro stimulated CD4 T cells from PBLs from patients LAU 470 (left) and LAU 814 (right). Percentages in the top right quadrants, frequencies of TNF $\alpha+$ within total CD4 T cells. 
A

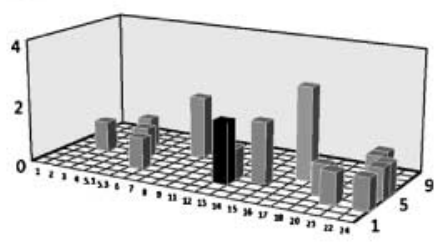

LAU 814

B
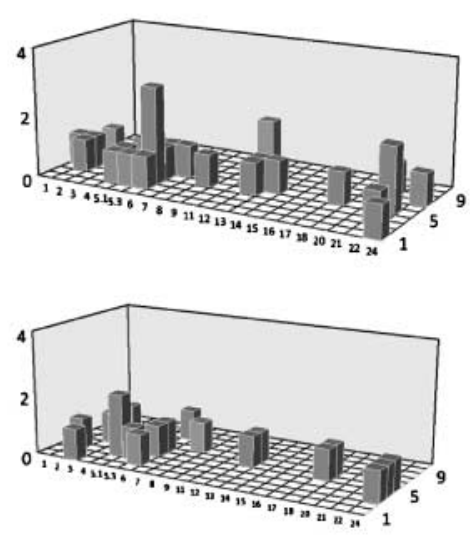

C

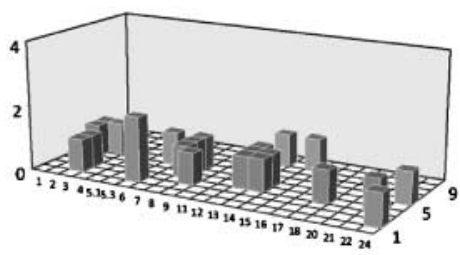

LAU 470

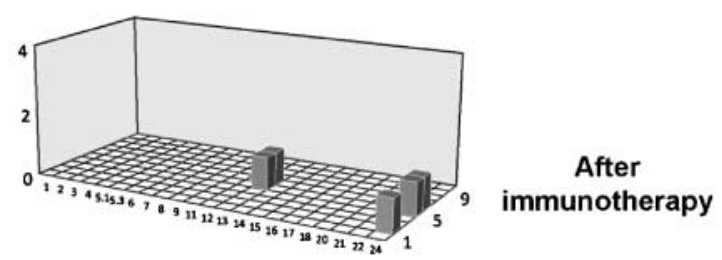

Figure 5. TCR $\vee \beta$ usage by ex vivo detected Melan- $\mathrm{A}_{25-36} \mathrm{CD} 4 \mathrm{~T}$ cells in PBLs from melanoma patients, before and after CTL-based immunotherapy. Graphs indicate TCR $V_{\beta}$ usage in ex vivo sorted five-cell samples from PBLs before (top) and after immunotherapy (bottom) for patient LAU 814 ( $A$ ), LAU 50 (B), and LAU 470 (C). $X$ axis, all the $\mathrm{V}_{\beta}$ tested; $Y$ axis, CDR3 product length; $Z$ axis, frequencies. Single filled bar, the only TCR clonotype (V $\beta 13$, CDR3 sequence SPHYNQPQ) that was identified twice among the 5-multimer+ cell aliquots in patient LAU 814.

\section{Discussion}

The main finding of our work is the direct ex vivo identification, using pMHCII multimers, of detectable frequencies of circulating Melan- $\mathrm{A}_{25-36}$-specific CD4 $\mathrm{T}$ cells in PBMCs of some DQ6+ HDs and the majority of DQ6+ metastatic melanoma patients. Remarkably, vaccination with an exact MHCI-restricted tumorassociated peptide modulates the phenotype, functionality, and TCR V $\beta$ usage of DQ6-Melan-A multimer+ CD4 T cells. Indeed, we describe for the first time major reductions in the levels of ex vivo detected FOXP3+ Melan- $\mathrm{A}_{25-36}$-specific CD4 $\mathrm{T}$ cells during the course of vaccination. The decline in antigen-specific FOXP3+ CD4 $\mathrm{T}$ cells is accompanied by a concomitant restoration of their peptide-specific proliferative potential and cytokine secretion. It is also associated with a significant restriction of their TCR V $\beta$ usage. Altogether our results suggest a previously unrecognized beneficial effect of therapeutic vaccination on a tumor antigen-specific CD4 T-cell population.

pMHCII multimers allow direct identification of antigen-specific CD4 T cells in various clinical situations in humans. However, due to the low frequencies of circulating antigen-specific CD4 T cells, this tool has not yet found the same wide usage as pMHCI multimers. In this regard, reports on the use of pMHCII multimers in the cancer field are still rare (28-30) and limited to the direct identification of specific cells after patients' immunization or after peptide IVS.

In HDs, both self- and tumor antigen-specific CD4 T cells have been identified by others. However, in contrast to the findings reported here, those specific CD4 $\mathrm{T}$ cells could not be directly identified ex vivo but only after multiple rounds of IVS of PBLs depleted of $\mathrm{CD} 4+\mathrm{CD} 25+\mathrm{T}$ cells (31). The Melan- $\mathrm{A}_{26-35}$ that is embedded in the HLA-DQ6-restricted epitope Melan- $\mathrm{A}_{25-36}$ is recognized by HLA-A2-restricted CD8 T cells, and high frequencies of naïve precursors can be identified directly ex vivo with HLA-A2/ Melan- $\mathrm{A}_{25-36}$ multimers in a large proportion of HLA-A2+ HDs (21, 32). Such massive repertoire is generated by a high level of thymic output and limited turnover in the periphery. Similarly, it can be speculated that Melan- $\mathrm{A}_{25-36} \mathrm{CD} 4 \mathrm{~T}$ cells might be able to escape thymic-negative selection and accumulate at relative high frequencies in the circulation. In this regard, we failed to ex vivo detect CD4 T cells specific for other tumor (e.g., NY-ESO-1) or viral (e.g., HA) antigens when using pMHCII multimers (data not shown).

The finding that Melan- $\mathrm{A}_{25-36} \mathrm{CD} 4 \mathrm{~T}$ cells are present at detectable levels in all but one of the patients' samples, before immunotherapy, and at significantly higher frequencies compared with HDs, argues for a tumor-induced expansion of these cells in the patients. The cells present a memory phenotype, and more interestingly, a large proportion expresses the transcription factor FOXP3. These features suggest that tumor progression selectively drives the amplification of memory tumor antigen-specific Tregs. Numerous reports have shown that Tregs are overrepresented in various cancer types $(26,33-35)$. Moreover, recent reports document on the existence of tumor-antigen specific Treg cells (36-40). However, no ex vivo data are currently available on the characterization of tumor antigen-specific Treg cells. We provide here evidence for the presence, in advanced stage melanoma patients, of relatively high numbers of circulating FOXP3+ Melan- $\mathrm{A}_{25-36}$ CD4 $\mathrm{T}$ cells, with low in vitro proliferative potential. These cells may contribute to the progression of the disease and suppress an effective antitumor response.

Little is known on the effect of vaccination on antigen-specific CD4 T cells in cancer patients. Few clinical trials have been reported in which melanoma patients were immunized with MHCII- in conjunction with MHCI peptides. If one trial showed that addition of MHCII-restricted epitopes to the vaccine formulation did not seem to improve clinical responses (41), another study reported on Th1/ Th2 responses induced in a small proportion of immunized patients (29). Furthermore, vaccination using full-length proteins of defined tumor antigens has resulted in the induction of integrated antibody, Th1, and CD8 T-cell responses (42). In a recent study on melanoma patients, it was reported that the use of Salmonella typhimurium engineered to deliver the antigen NYESO-1 elicits CD4 Th1 cells in vitro, which are able to recognize naturally processed antigen and are resistant to suppression by Tregs (43). Finally, in a clinical trial in breast cancer patients, 
vaccination with a MHCI-restricted HER2/neu peptide resulted in a significant decrease in circulating Tregs and TGF $\beta$ serum levels in the majority of patients (44). Here, we describe for the first time the effect of immunization using a MHCI-restricted peptide on tumor antigen-specific CD4 T cells. We observe that the same Melan-A 26-35(A27L) peptide that induces strong tumor-specific CD8 T-cell responses is able to influence circulating Melan- $\mathrm{A}_{25-36} \mathrm{CD} 4 \mathrm{~T}$ cells in HLA-DQ6+ patients. Indeed, surprisingly, the Melan- $\mathrm{A}_{25-36}$ FOXP3+ and helper CD4 T-cell ratio is reversed during the course of vaccination. This effect seems to be selective because the levels of FOXP3+ cells among the multimer- CD4 T cells remained stable during time. These observations are in contrast with results obtained in mouse tumor models, where immunization of tumorbearing animals with tumor antigen recombinant vaccinia virus resulted in the expansion of tumor-induced Tregs $(45,46)$. These discrepancies might be explained by the fact that our vaccination protocol includes a peptide, Melan- $\mathrm{A}_{26-35(\mathrm{~A} 27 \mathrm{~L}) \text {, which simulta- }}$ neously targets CD4 and CD8 T cells. In this regard, it has been reported that immunization of animals bearing methylcholanthrene-induced sarcomas with the addition of a CTL epitope to the standard protocol consisting in plasmids encoding self-antigens resulted in a switch from tumor progression due to expansion of Tregs to an augmented CTL activity and T-cell help. (47).

In addition to the drop in FOXP3+ Melan- ${ }_{25-36}$ CD4 $\mathrm{T}$ cells, immunization also leads to a significant augmentation of the in vitro proliferative capacity of these cells, as well as to the ability to secrete Th1 cytokines (e.g., TNF $\alpha$ ). As suggested recently (27), the combined assessment of FOXP3 expression and cytokine profiles allows to distinguish regulatory from activated CD4+CD25+ $\mathrm{T}$ cells. The molecular and cellular mechanisms underlying this observation remain poorly understood. One possibility is that vaccine components, either acting directly on CD4 $\mathrm{T}$ cells, or primarily on CD8 T cells and indirectly on CD4 T cells, promote the generation/expansion of helper Melan- $\mathrm{A}_{25-36} \mathrm{CD} 4$ $\mathrm{T}$ cells. Thus far, our attempts to reproduce in vitro the ex vivo observations have failed, probably due to the complexity of the in vivo situation that cannot be efficiently mimicked in an artificial in vitro system. To gain further insights into the in vivo mechanism, we compared the TCR V $\beta$ usage of ex vivo detected Melan- $\mathrm{A}_{25-36}$ CD4 T cells, in the same patient, before and after immunotherapy. The number of TCR V $\beta$ segments was significantly reduced in the specific CD4 T cells from postvaccination samples compared with the prevaccination baseline values. Thus, it is possible that vaccination favored the selective expansion of FOXP3- specific CD4 $\mathrm{T}$ cells. Whether the FOXP3+ specific CD4 $\mathrm{T}$ cells underwent apoptosis (48) or simply became undetectable by the spectratyping technique remains to be addressed. In parallel, we have previously shown that specific CD8 T-cell responses expanded by vaccination are characterized by the persistence of only a small number of highly active and dominant clonotypes $(49,50){ }^{8}$

When feasible, additional ex vivo analyses directly on tumorbearing tissues will allow to gain a more detailed picture on the redistribution of antigen-specific CD4 $\mathrm{T}$ cells upon immunization. Eventually, parameters to correlate immunologic responses with clinical benefit may be identified.

In conclusion, this study shows for the first time that vaccination with an exact MHC-I antigenic peptide leads not only to the efficient induction of MHC-I restricted CD8 T cells but may also drive the shift from a FOXP3+ MHC II-restricted peptide-specific CD4 T-cell population to a Th1-like specific response. Because the same peptide can be recognized by both CD8 and CD4 T cells, it is tempting to speculate that this class of peptides may be advantageous for vaccination. This hypothesis needs to be tested in appropriate animal models, in which the underlying mechanism(s) may be addressed.

\section{Disclosure of Potential Conflicts of Interest}

No potential conflicts of interest were disclosed.

\section{Acknowledgments}

Received 6/17/09; revised 8/19/09; accepted 8/19/09; published OnlineFirst 10/6/09.

Grant support: P. Romero was funded in part by a grant from the European Union FP6 program, "Cancerimmunotherapy."

The costs of publication of this article were defrayed in part by the payment of page charges. This article must therefore be hereby marked advertisement in accordance with 18 U.S.C. Section 1734 solely to indicate this fact.

We thank the patients for study participation and blood donation, the hospital staff at the Centre Pluridisciplinaire d'Oncologie, and E. Devêvre for excellent assistance with flow cytometry analysis and cell sorting.

\footnotetext{
${ }^{8}$ Unpublished observations.
}

\section{References}

1. Melief CJ, van der Burg SH. Immunotherapy of established (pre)malignant disease by synthetic long peptide vaccines. Nat Rev Cancer 2008;8:351-60.

2. Rosenberg SA, Restifo NP, Yang JC, Morgan RA, Dudley ME. Adoptive cell transfer: a clinical path to effective cancer immunotherapy. Nat Rev Cancer 2008, 8:299-308.

3. Mahnke YD, Speiser D, Luescher IF, Cerottini JC Romero P. Recent advances in tumour antigen-specific therapy: in vivo veritas. Int J Cancer 2005;113:173-8.

4. van der Bruggen $P$, Traversari $C$, Chomez $P$, et al. A gene encoding an antigen recognized by cytolytic $\mathrm{T}$ lymphocytes on a human melanoma. Science 1991;254:1643-7.

5. Rosenberg SA. Shedding light on immunotherapy for cancer. N Engl J Med 2004;350:1461-3.

6. Parmiani G, Castelli C, Santinami M, Rivoltini L. Melanoma immunology: past, present and future. Curr Opin Oncol 2007;19:121-7.
7. Hofbauer GF, Kamarashev J, Geertsen R, Boni R, Dummer R. Melan A/MART-1 immunoreactivity in formalin-fixed paraffin-embedded primary and metastatic melanoma: frequency and distribution. Melanoma Res 1998;8:337-43.

8. Castelli C, Storkus WJ, Maeurer MJ, et al. Mass spectrometric identification of a naturally processed melanoma peptide recognized by $\mathrm{CD} 8+$ cytotoxic T lymphocytes. J Exp Med 1995;181:363-8.

9. Benlalam H, Linard B, Guilloux Y, et al. Identification of five new HLA-B*3501-restricted epitopes derived from common melanoma-associated antigens, spontaneously recognized by tumor-infiltrating lymphocytes. J Immunol 2003;171:6283-9.

10. Romero P, Gervois N, Schneider J, et al. Cytolytic T lymphocyte recognition of the immunodominant HLA$\mathrm{A}^{*}$ 0201-restricted Melan-A/MART-1 antigenic peptide in melanoma. J Immunol 1997;159:2366-74.

11. Schneider J, Brichard V, Boon T, Meyer zum Buschenfelde $\mathrm{KH}$, Wolfel T. Overlapping peptides of melanocyte differentiation antigen Melan-A/MART-1 recognized by autologous cytolytic $\mathrm{T}$ lymphocytes in association with HLA-B45.1 and HLA-A2.1. Int J Cancer 1998;75:451-8

12. Bioley G, Jandus C, Tuyaerts S, et al. Melan-A/MART1-specific CD4 T cells in melanoma patients: identification of new epitopes and ex vivo visualization of specific T cells by MHC class II tetramers. J Immunol 2006;177: 6769-79.

13. Valmori D, Levy F, Godefroy E, et al. Epitope clustering in regions undergoing efficient proteasomal processing defines immunodominant CTL regions of a tumor antigen. Clin Immunol 2007;122:163-72.

14. Jackson H, Dimopoulos N, Mifsud NA, et al. Striking immunodominance hierarchy of naturally occurring $\mathrm{CD} 8+$ and CD4+ T cell responses to tumor antigen NYESO-1. J Immunol 2006;176:5908-17.

15. Surman S, Lockey TD, Slobod KS, et al. Localization of CD4+ T cell epitope hotspots to exposed strands of HIV envelope glycoprotein suggests structural influences 
on antigen processing. Proc Natl Acad Sci U S A 2001;98: 4587-92.

16. Kim SK, DeMars R. Epitope clusters in the major outer membrane protein of Chlamydia trachomatis. Curr Opin Immunol 2001;13:429-36.

17. Valmori D, Fonteneau JF, Lizana CM, et al. Enhanced generation of specific tumor-reactive CTL in vitro by selected Melan-A/MART-1 immunodominant peptide analogues. J Immunol 1998;160:1750-8.

18. Lienard D, Rimoldi D, Marchand $\mathrm{M}$, et al. Ex vivo detectable activation of Melan-A-specific T cells correlating with inflammatory skin reactions in melanoma patients vaccinated with peptides in IFA. Cancer Immun 2004;4:4.

19. Ayyoub M, Zippelius A, Pittet MJ, et al. Activation of human melanoma reactive CD8+ T cells by vaccination with an immunogenic peptide analog derived from Melan-A/melanoma antigen recognized by $\mathrm{T}$ cells- 1 . Clin Cancer Res 2003;9:669-77.

20. Speiser DE, Lienard D, Rufer N, et al. Rapid and strong human CD8+ T cell responses to vaccination with peptide, IFA, and CpG oligodeoxynucleotide 7909. J Clin Invest 2005;115:739-46.

21. Pittet MJ, Valmori D, Dunbar PR, et al. High frequencies of naive Melan-A/MART-1-specific CD8(+) $\mathrm{T}$ cells in a large proportion of human histocompatibility leukocyte antigen (HLA)-A2 individuals. J Exp Med 1999;190:705-15.

22. Romero P, Dunbar PR, Valmori D, et al. Ex vivo staining of metastatic lymph nodes by class I major histocompatibility complex tetramers reveals high numbers of antigen-experienced tumor-specific cytolytic T lymphocytes. J Exp Med 1998;188:1641-50.

23. Rufer N, Reichenbach P, Romero P. Methods for the ex vivo characterization of human $\mathrm{CD} 8+\mathrm{T}$ subsets based on gene expression and replicative history analysis. Methods Mol Med 2005;109:265-84.

24. Rufer N, Zippelius A, Batard P, et al. Ex vivo characterization of human CD8+ $\mathrm{T}$ subsets with distinct replicative history and partial effector functions. Blood 2003;102:1779-87.

25. Dumont-Girard F, Roux E, van Lier RA, et al. Reconstitution of the T-cell compartment after bone marrow transplantation: restoration of the repertoire by thymic emigrants. Blood 1998;92:4464-71.

26. Ahmadzadeh M, Felipe-Silva A, Heemskerk B, et al. FOXP3 expression accurately defines the population of intratumoral regulatory $\mathrm{T}$ cells that selectively accumulate in metastatic melanoma lesions. Blood 2008;112:4953-60.

27. Kryczek I, Liu R, Wang G, et al. FOXP3 defines regulatory $\mathrm{T}$ cells in human tumor and autoimmune disease. Cancer Res 2009;69:3995-4000.

28. Lemaitre F, Viguier M, Cho MS, et al. Detection of low-frequency human antigen-specific $\mathrm{CD} 4(+) \mathrm{T}$ cells using MHC class II multimer bead sorting and immunoscope analysis. Eur J Immunol 2004;34:2941-9.

29. Wong R, Lau R, Chang J, et al. Immune responses to a class II helper peptide epitope in patients with stage III/ IV resected melanoma. Clin Cancer Res 2004;10:5004-13. 30. Zhang Y, Renkvist N, Sun Z, et al. A polyclonal antivaccine $\mathrm{CD} 4 \mathrm{~T}$ cell response detected with HLA-DP4 multimers in a melanoma patient vaccinated with MAGE-3.DP4-peptide-pulsed dendritic cells. Eur J Immunol 2005;35:1066-75.

31. Danke NA, Koelle DM, Yee C, Beheray S, Kwok WW Autoreactive T cells in healthy individuals. J Immuno 2004:172:5967-72.

32. Voelter V, Rufer N, Reynard S, et al. Characterization of Melan-A reactive memory CD8+ T cells in a healthy donor. Int Immunol 2008;20:1087-96.

33. Curiel TJ, Coukos G, Zou L, et al. Specific recruitment of regulatory $\mathrm{T}$ cells in ovarian carcinoma fosters immune privilege and predicts reduced survival. Nat Med 2004;10:942-9. 34. Harlin H, Kuna TV, Peterson AC, Meng Y, Gajewski TF. Tumor progression despite massive influx of activated CD8(+) $\mathrm{T}$ cells in a patient with malignant melanoma ascites. Cancer Immunol Immunother 2006;55:1185-97. 35. Jandus C, Bioley G, Speiser DE, Romero P. Selective accumulation of differentiated FOXP3(+) CD4 (+) T cells in metastatic tumor lesions from melanoma patients compared to peripheral blood. Cancer Immunol Immunother 2008;57:1795-805.

36. Nishikawa H, Jager E, Ritter G, Old LJ, Gnjatic S. CD4+ CD25+ regulatory T cells control the induction of antigen-specific CD4+ helper $\mathrm{T}$ cell responses in cancer patients. Blood 2005;106:1008-11.

37. van der Burg SH, Piersma SJ, de Jong A, et al. Association of cervical cancer with the presence of CD4+ regulatory $\mathrm{T}$ cells specific for human papillomavirus antigens. Proc Natl Acad Sci U S A 2007;104:12087-92. 38. Vence L, Palucka AK, Fay JW, et al. Circulating tumor antigen-specific regulatory $\mathrm{T}$ cells in patients with metastatic melanoma. Proc Natl Acad Sci U S A 2007; 104:20884-9.
39. Wang HY, Lee DA, Peng G, et al. Tumor-specific human CD4+ regulatory $\mathrm{T}$ cells and their ligands: implications for immunotherapy. Immunity 2004:20:107-18.

40. Wang HY, Peng G, Guo Z, Shevach EM, Wang RF. Recognition of a new ARTCl peptide ligand uniquely expressed in tumor cells by antigen-specific CD4+ regulatory T cells. J Immunol 2005;174:2661-70.

41. Phan GQ, Touloukian CE, Yang JC, et al. Immunization of patients with metastatic melanoma using both class I- and class II-restricted peptides from melanomaassociated antigens. J Immunother 2003;26:349-56.

42. Valmori D, Souleimanian NE, Tosello V, et al Vaccination with NY-ESO-1 protein and CpG in Montanide induces integrated antibody/Thl response and CD8 T cells through cross-priming. Proc Natl Acad Sci U S A 2007;104:8947-52.

43. Nishikawa H, Tsuji $T$, Jager E, et al. Induction of regulatory $\mathrm{T}$ cell-resistant helper $\mathrm{CD} 4+\mathrm{T}$ cells by bacterial vector. Blood 2008;111:1404-12.

44. Hueman MT, Stojadinovic A, Storrer CE, et al. Levels of circulating regulatory $\mathrm{CD} 4+\mathrm{CD} 25+\mathrm{T}$ cells are decreased in breast cancer patients after vaccination with a HER2/neu peptide (E75) and GM-CSF vaccine. Breast Cancer Res Treat 2006;98:17-29.

45. Zhou G, Drake CG, Levitsky HI. Amplification of tumor-specific regulatory $\mathrm{T}$ cells following therapeutic cancer vaccines. Blood 2006;107:628-36.

46. Zhou G, Levitsky HI. Natural regulatory T cells and de novo-induced regulatory $\mathrm{T}$ cells contribute independently to tumor-specific tolerance. J Immunol 2007;178: 2155-62.

47. Nishikawa H, Kato T, Tawara I, et al. IFN- $\gamma$ controls the generation/activation of $\mathrm{CD} 4+\mathrm{CD} 25+$ regulatory $\mathrm{T}$ cells in antitumor immune response. J Immunol 2005; 175:4433-40.

48. Glisic S, Klinker M, Waukau J, et al. Genetic association of HLA DQB1 with CD4+CD25+(high) T-cell apoptosis in type 1 diabetes. Genes Immun 2009;10:334-40.

49. Derre L, Bruyninx M, Baumgaertner $\mathrm{P}$, et al. In vivo persistence of codominant human CD8+ T cell clonotypes is not limited by replicative senescence or functional alteration. J Immunol 2007;179:2368-79.

50. Speiser DE, Baumgaertner $\mathrm{P}$, Barbey $\mathrm{C}$, et al. A novel approach to characterize clonality and differentiation of human melanoma-specific $\mathrm{T}$ cell responses: spontaneous priming and efficient boosting by vaccination. J Immunol 2006;177:1338-48. 


\section{Tumor Antigen-Specific FOXP3+ CD4 T Cells Identified in Human Metastatic Melanoma: Peptide Vaccination Results in Selective Expansion of Th1-like Counterparts}

Camilla Jandus, Gilles Bioley, Danijel Dojcinovic, et al.

Cancer Res 2009;69:8085-8093. Published OnlineFirst October 6, 2009.

$\begin{array}{ll}\text { Updated version } & \begin{array}{l}\text { Access the most recent version of this article at: } \\ \text { doi:10.1158/0008-5472.CAN-09-2226 }\end{array}\end{array}$

Supplementary Access the most recent supplemental material at:

Material http://cancerres.aacrjournals.org/content/suppl/2009/10/01/0008-5472.CAN-09-2226.DC1.ht $\mathrm{ml}$

Cited Articles This article cites by 50 articles, 29 of which you can access for free at:

http://cancerres.aacrjournals.org/content/69/20/8085.full.html\#ref-list-1

Citing articles This article has been cited by 3 HighWire-hosted articles. Access the articles at:

http://cancerres.aacrjournals.org/content/69/20/8085.full.html\#related-urls

E-mail alerts Sign up to receive free email-alerts related to this article or journal.

Reprints and To order reprints of this article or to subscribe to the journal, contact the AACR Publications

Subscriptions Department at pubs@aacr.org.

Permissions To request permission to re-use all or part of this article, contact the AACR Publications Department at permissions@aacr.org. 